\title{
On Chinese tourism e-business development on current stage
}

\author{
Yong Jin 1, 2, Xu song Xu 1 \\ 1 School of Economic and Management, Wuhan University, P.R.China, \\ 430070 \\ 2 School of Management, Hubei University of Technology, P.R.China, \\ 430068 \\ jy6509@163.com,jy6509@21cn.com
}

\begin{abstract}
By analyzing the economy and technology background of appearance of tourism e-business, the paper describe the concept of tourism ebusiness and it's operation mode in order to master this modern alternative deeply and all-round. The author emphasizes on the discussion of the interpromotion and inter-development relationship between e-business and tourism economy, meanwhile forecasts the future of Chinese tourism e-business based on the analysis of difficult position we are facing now in tourism e-business. Combining with successful cases, suggestions on the development of tourism e-business are put forward.
\end{abstract}

\section{Introduction}

Global economy is entering into the information time, digital economy, cybereconomy and information economy is gradually becoming the main trend of economy development. As the main economy and trade method in 21 st century, ebusiness will bring great innovation to all countries' economy and become the growth motivation of economy and a new growth point.

\section{Concept of tourism e-business}

The so-called tourism enterprises are new business activities linked through computer calculation technology, electronic communication technology and enterprise buying and selling network system which based on internet technology provided by Internet. [1] They include on-line message sending and receiving; on-

Please use the following format when ciling this chapter:

Jin, Y., Xu, X., 2007, in IFIP International Federation for Information Processing, Volume 251, Integration and Innovation Orient to L-Society Volume 1, Wang, W. (Lds), (Boston: Springer), pp. 586-592. 
line order, payment, customer service and other on-line selling, on-line before-selling recommendation and after-sale service; and various business activities like market investigation and analysis, financial accounting and manufacture arrangement which made use of Internet. It is a combination mode of information flow that based on information network poly-technology and business operation procedure. Functions of tourism e-business can be summed up to: tourism enterprises marketing information proclaim; EDI (Electronic Date Interchange), on-line order, e-account and on-line payment; service delivery, opinion seeking and consulting, trading management and so on. With the high speed development of information technology, as a new trading method and business mode, e-business is entering into every region of traditional business which involves tourism industry at an unprecedented rate.

\section{Necessity of the development of tourism e-business}

\subsection{From market competition's standpoint}

From external factors, after we entered WTO, with mature e-Business experience, abundant fund and first-class service, foreign tourism companies will be tremendous impact to Chinese tourism market. While from internal factors, tourism industry is the universal "sun-rise business" which has a good long term potential. Foreign investors want to occupy this market, however the original market occupants want to consolidate and expand their territory. It is an austere challenge for tourism enterprises to gain an advantage in competitions. Confronting with fierce market competition, it is necessary for tourism industry to take some measure to enlarge their scope, in order to realize the scale economy, reduce the margin cost and improve the efficiency. However expand in traditional way might leads to inflated departments and over-sized employees, which will lead to the inefficiency of management and costly payment. However tourism e-business can provide tourism enterprises with e-Business application operation platform, on which tourism product designation and suppliers purchasing can be easily completed, meanwhile, external advertisement and promotion, on-line selling enrollment, internal activity cooperation and communication can also be done there. All those can maintain the high efficiency and smooth for tourism operation. By using this, enterprises can improve their efficiency, reduce employees, lower cost and strengthen the enterprises' competition ability.

\subsection{From tourism enterprises' standpoint}

Since tourism industry belongs to service industry, its development depends on the level of customers' satisfaction on service they provided. It asks tourism enterprises to provide customers with abundant tourism attraction information timely, exactly and elaborately. At the same time, tourism enterprises should be aware of domestic and international customer market information, requirement of customer and provide various relevant services according to customers' requirement. Break up the region limitation, integrate all kinds of tourism resource to the maximum extend and pump new power into tourism enterprises to a large extent. 


\subsection{From customers' standpoint}

With the improvement of people's material life, customers' psychological demand entered into a higher level, target of tourism increased to a high level of life experience, self-perfecting and self-value realization. People's tourism requirement is improving everyday, they would like to have an overall knowledge of all related information they need before they go out, and expect to enjoy all convenient and quick service. The appearance of tourism e-business meets the customers'

requirement. Travelers can have a look of the brief introduction of the tourism company and pictures of the tourism spot, be aware of the journey, price quotation, accommodation and other information, meanwhile they can order service and tourism items through Internet.

\section{Main problems that existed in Chinese tourism e-business}

Problems that restrict the development of our tourism network are not only technology issues, but also operation environment existed in traditional tourism business and the whole development level of society economy. Main problems we are confronting of the development of our tourism internet are:

\subsection{Imperfect information search}

When searching tourism information on line, a big problem customers are facing is that how can they find the exact information through various websites, and obtain it at the lowest price. The search engine looks quite easy: user entered a key inquire word and the search engine will seek in the data base according to the key word and return with the most appropriate WEB page link. However according to the latest research result, currently at least 10 trillion web pages needs to build up a search engines on the internet, while existing search engines can only work 5 trillion web pages. There are still half of them can not use search engine. [2] This is not mainly because of the technology reason; on-line sellers want to protect the privacy of their product price. So when users browse information on-line, they have to search website by website, until they find a satisfied one.

\subsection{Lower security of trading}

Security of trading is still a main factor that influent the development of tourism ebusiness. Owing to the quick prevailing of Internet, tourism e-business causes widely attention and be considered to be the most potential new growth point of future IT industry. While when deal on the open network, how to make sure the security of data transfer is one of the most important factors that decide whether tourism ebusiness can be popularized. Investigation companies had ever taken the on-line survey about the application anticipation of tourism e-business. When asked why unwilling to shop on line, most of the worries are about the lost of credit card 
information in case of attacking by Hacker. So part of the people are not willing to use tourism e-business for worrying about the security issue. Security becomes the biggest obstacle of tourism e-business.

\subsection{Lack of credit guarantee}

Another obstacle of building up tourism e-business is the lack of credit. How is the trade credit of tourism enterprises? Are products we ordered in screen consistent with the real tourism? How about the quality? Due to the existing problems of the reliability of TV-ads, fears of on-line shopping will get more.

\subsection{Similar operation mode}

Main e-business business of tourism websites includes air-ticket; hotel and tourism group booking and every tourism website have them. When websites regard themselves as travel agencies, they found that there is nearly no predominance of their service comparing with traditional travel agencies, hotel booking center and airticket selling company. Therefore, to make profit, travel websites must provide better service, better products, or seeking new foothold and development opportunities, or quickly scale up their sales column. Otherwise, websites will get lost before nail down better development mode.

\subsection{Guarantee of off-line service}

Usually Internet companies lay particular stress on information flow and capital flow. Tourism websites should combine some good traditional marketing mode when they employ Internet to maximum advantages, only in this way can they provide users with integrated service. In fact, most network companies' off-line service can not get guarantee.

\subsection{Disadvantage of payment method and consumption habit}

In foreign countries, there is a close relationship between popularization of credit card, use of internet and good development of e-Business. In china, credit cards are not widely used and this way of payment is not be accepted by the society; meanwhile, not many Chinese get used to on-line consumption. Consumers' personal and companies' credit standing have not yet been set up on line and this must bring great obstacle to the development of tourism e-business.

\section{7 lack of sustain of main tourism industry}

Multitudinous tourism websites are lack of thorough and deep understanding of tourism industry when they layout, they cannot correctly find the breaking through point and therefore hardly to form their own characteristic and selling point. Usually 
they copy from foreign websites' existing mode and become the Chinese edition of developed countries' websites, for example American and Canada.

\section{Countermeasures of development of Chinese tourism e-business}

\subsection{Characteristic orientation}

Tourism industry is a typical service industry and tourism e-business is service oriented. According to CNNIC's report, among main factors that user select ISP, connecting speed takes the first place with $43 \%$, service takes the second place with $24 \%$; while among main factors of successful websites, service with plenty of information, in-time update and attractiveness takes the first place with 63.35\%.[3] therefore, tourism website want to have higher visiting column and large quantity of trade, should have on-line trading platform which can provide special, multi-angle, multi-profile, diversified and good quality service to attract various kind of consumer. From case analysis below, we will have more direct understanding.

Ctrip.com holds items like routing, room-booking, ticket-booking and community, and the room-booking center whose scale is among the first three, its market orientation focus on self-tourism and business-tourism. Sales volume reached at 10 million RMB this May and hopefully accumulated to 1 trillion at the end of this year. Ctrip.com is built up from gateway model, depended on profit from roombooking; it aims at tourism Service Corporation. Before Ctrip.com, main business of tourism websites in China are information providing, for the first time tourism websites oriented at the service agency of tourism industry cause of the entrance of Ctrip.com. Revelation Ctrip.com brings to us is not only the technology promotion from Internet, but more important the re-definition of tourism service it digs out. [4] Xoyo.com oriented at on-line hotel booking. Among various tourism resources, hotel industry is the easiest one of networking; moreover hotel booking is the most profitable part among e-Business. Investment always asks for return and blows off cyber-economy foam, Xoyo.com selected the most realistic method. Not pursuing high, great and integration, Xoyo.com established itself in brand-building and service-pursuing.

Sotrip.com locates its market breaking through point at culture tourism, which has profound inside culture information. The website oriented at "network edition of China national geography magazine", which currently has title of columns like tourism culture, tourism literature, community, professional homepage, theme tourism and so on. Concept of Sotrio.com is to grasp the great requirement of individuation that new age tourism asks for, then initiate "traveling all around, getting to know things and understanding diversified survival state; exploring deep and serene, meeting humanities and seeking trace of the ancients; visiting hardship and dangers, realizing spirit and feeling the free artistic conception of oneness of man and nature". Sotrip.com even did not plan to take business of on-line tourism group, ticket-booking, room-booking and so on, as for the way of making profit they have their own idea: consumer is the leader of digital economy, enterprises in the future need to take real time analysis and forecast consumer information, according to which provide customer-made product and service, in this way can they have 
necessary customer information. High visiting column plus customer loyalty plus sufficient and efficient customer data equals to the websites' future profit space, unlimited potential hided behind their new version.

\subsection{Capital, resource, technology and market}

Rushing forward is a rule in network industry. Winner is the one that keep merging the competitors after life and death struggles. Economy discipline from "all flowers bloom together" to "several branches outshine others" will finally complete the reorganization of capital, resource, technology and market. On the other facet, integration and strategy alliance between tourism websites and traditional tourism corporations is the main trend.

Tourism e-business breaks up the traditional mode and method and builds up modern tourism management information system, which avoids drawbacks of large organization and inefficient management from traditional scale expanding and form new structure of tourism development which is scaled, industry rationalized and standardized. At the same time, backed against traditional tourism industry and firsthand tourism material in detail provided by traditional corporations, tourism websites' content can get clear-cut and unique feature and service style. Tourism websites can also charge fees from services to Tourism Corporation to maintain its normal running and make profits. Tactic and strategy of Tourism Corporation and websites is a win-win measure. [5] Alliance method between Tourism Corporation and websites can be diversified and marketalized. Alliance can be done through capital way to take strategy re-organization, to form large-sized corporation group, it can also be done through tourism websites' netting of traditional tourism corporation. Tourism corporations and tourism websites can optimize their resources by forming corporation group and operation of capital, this makes management and operation easier and at the same time occupies double-themes of both sun-rise industry and network \& high-tech, which makes financing from listing easier and promotes its core competition advantages. It is a good way for small and medium sized enterprises to consign tourism websites to finish their network building.

\subsection{Operation method and scope}

Among more than 3000 tourism agencies in china, $90 \%$ of them are small and medium sized, which continue traditional manual operation, operations with only a telephone plus a fax machine is not rare.[6] Those diversified, small and weak enterprise need network to reach low cost and efficiency, change the disorder situation of customer resource management by systematization. Large tourism service corporations emphasis good connection between subsidiaries and users through companies' network.

To develop tourism e-business, we also need to widen our field of observation, provide services with multi-language and different level of requirement according to our customer resource, like English edition, Japanese edition, and French edition and so on. For example, Sotrip.com has special English edition, compare with it, foreign websites can not deeply grasp Chinese culture's quintessence; while most of the 
English edition of national websites are only translation of Chinese edition without taking into account the requirement difference between foreign and national customer. With the quick increase of Chinese entry tourism, this huge potential market is our important target in developing our tourism industry. At the time that foreign websites is coming, it seems to be more precious for our national websites to have the lofty sentiments to go out.

\section{Conclusion}

Tourism e-business is of special significance in reconstructing traditional inefficient business operation method and pushing up the promotion of market economy quality. However, problems still exist in the real development of tourism e-business, for example, unprofitable issue, payment issue, information problem and security problems and so on. Those problems are great obstacles for the development of tourism e-business. Our overall e-business is still on the stage of beginning, measurements of on-line security guarantee, identification of responsibility are universally be lacked of, big environments of e-Business still need to be improved. As the government and enterprises, we should regard "high starting point and internationalization" as the principle to support and push the development of tourism e-business, compromise tradition and modern, then tourism industry in information age will develop continuous and healthy.

\section{Reference}

1. L.D. Zhao, E-Business Theory and Practice, Beijing: People's Post and Telecommunication Press, 2001.

2. J.X. Zhang, (2001), "Opportunity and Challenge Tourism Industry's Information Management confronts under Network Environment", Science \& Technology Progress and Policy, 2001, (6):131-132.

3. X.L Xu, C.F. Jiang, (2001), "Development of Travel Agency in Network Time", Tourism Science, 2001, (2):29-32.

4. M.X.Guo, (1999), "The fittest can survive; Development Tactic of Tourism Industry under the Impact of International Internet", Guilin Institution of Tourism Journal, 1999,(3):23-28.

5. L.Y. Zhang, Current Situation and Development Trend of our Tourism Internet, Beijing: China Travel and Tourism Press, 2000.

6. X.A. Wei, S.M. Zhang, Framing Conception of Chinese Tourism Industry EBusiness Development, Beijing: China Travel and Tourism Press, 2000.

7. China Tourism News, [N].20050101-20051228. 